\title{
Pacing in age-group freestyle swimmers at The XV FINA World Masters Championships in Montreal 2014
}

\author{
Nikolaidis, Pantelis T ; Knechtle, Beat
}

\begin{abstract}
Pacing strategies have been investigated for elite-standard freestyle swimmers, but little is known about pacing in age-group freestyle swimmers. We investigated changes in swimming time across distances in 4,481 women and men swimmers who competed in 100, 200, 400, and $800 \mathrm{~m}$ freestyle age groups from 25-29 years to 90-94 years in the FINA World Masters Championships 2014. In 100 to $800 \mathrm{~m}$, there was a small lap $\times$ sex interaction $(\mathrm{P}<0.001,0.033 \leq \eta(2) \leq 0.045)$ whereby women had larger lap-to-lap changes in swimming time than men. From 100 to $800 \mathrm{~m}$, there were moderate to large lap ×age group interactions $(\mathrm{P}<0.001,0.054 \leq \eta(2) \leq$ 0.235), i.e., pacing patterns differed by age groups. There were small main effects of lap on time in 100, 200, 400 and $800 \mathrm{~m}$ freestyle events $(\mathrm{P}<0.001,0.033 \leq \eta(2) \leq 0.045)$. In summary, (i) the largest increase in swimming time occurred during the second lap and a decrease in time occurred during the last lap, except in the $100 \mathrm{~m}$, and (ii) the effect of participants' sex on lap time indicated larger percentage changes of pacing in women than in men. These findings should help coaches to develop age- and event-tailored pacing strategies.
\end{abstract}

DOI: https://doi.org/10.1080/02640414.2016.1213412

Posted at the Zurich Open Repository and Archive, University of Zurich ZORA URL: https://doi.org/10.5167/uzh-127089

Journal Article

Accepted Version

Originally published at:

Nikolaidis, Pantelis T; Knechtle, Beat (2017). Pacing in age-group freestyle swimmers at The XV FINA World Masters Championships in Montreal 2014. Journal of Sports Sciences, 35(12):1165-1172.

DOI: https://doi.org/10.1080/02640414.2016.1213412 
Pacing in age-group freestyle swimmers at

Running head: Pacing in master swimmers

5

6

Pantelis T. Nikolaidis ${ }^{1}$, Beat Knechtle ${ }^{2,3}$

8

Department of Physical and Cultural Education, Hellenic Army Academy,

Corresponding author

Prof. Dr. med. Beat Knechtle

Facharzt FMH für Allgemeinmedizin

Gesundheitszentrum St. Gallen

Vadianstrasse 26

9001 St. Gallen

Switzerland

Telefon

Telefax

+41(0) 712269300

e-Mail

+41(0) 712269301

beat.knechtle@hispeed.ch 


\section{$37 \quad$ Abstract}

\section{(1)}

Pacing strategies have been investigated for elite-standard freestyle swimmers, but little is known about pacing in age-group freestyle swimmers. We investigated changes in swimming time across distances in 4,481 women and men swimmers who competed in $100 \mathrm{~m}, 200 \mathrm{~m}, 400 \mathrm{~m}$, and $800 \mathrm{~m}$ freestyle age groups from 25-29 years to $90-94$ years in the FINA World Masters Championships 2014. In $100 \mathrm{~m}$ to $800 \mathrm{~m}$, there was a small lapxsex interaction $\left(P<0.001,0.033 \leq \eta^{2} \leq 0.045\right)$ whereby women had larger lap-to-lap changes in swimming time than men. From $100 \mathrm{~m}$ to $800 \mathrm{~m}$, there were moderate to large lapxage group interactions $\left(P<0.001,0.054 \leq \eta^{2} \leq\right.$ 0.235) i.e. pacing patterns differed by age groups. There were small main effects of lap on time in $100 \mathrm{~m}, 200 \mathrm{~m}, 400 \mathrm{~m}$ and $800 \mathrm{~m}$ freestyle events $\left(P<0.001,0.033 \leq \eta^{2}\right.$ $\leq 0.045)$. In summary, $(i)$ the largest increase in swimming time occurred during the second lap and a decrease in time occurred during the last lap, except in the $100 \mathrm{~m}$, and (ii) the effect of participants' sex on lap time indicated larger percentage changes of pacing in women than in men. These findings should help coaches to develop ageand event-tailored pacing strategies.

(1)

Key words: athlete, master, age group, performance 


\section{Introduction}

61 There has been an increasing scientific interest about master athletes, because they have been considered as a model of successful ageing (Tanaka \& Seals, 2008). Swimming is one of the most popular sports with many older people practising it at a recreational level and a large number of master athletes (whose number has increased during the last decades) participating in official sport events such as the FINA (Fédération Internationale de Natation) World Masters Championship (Rubin \& Rahe, 2010). Most of the studies on master swimmers have focused on physiological and biomechanical determinants of performance and how these determinants varied by age (Reaburn \& Dascombe, 2008; Tanaka \& Seals, 2008), whereas pacing strategies, which are also a factor of performance, have been less studied.

71 Pacing in sports describes the strategy of an athlete by which effort is managed across an exercise bout for a specific goal and in the knowledge of the likely demands of the task (Edwards \& Polman, 2012). Abbiss and Laursen (2008) described six pacing strategies in athletic performance such as negative pacing (i.e. increase in speed over time), positive pacing (i.e. continuous slowing over time), all-out pacing (i.e. maximal speed possible), even pacing (i.e. same speed over time), parabolic-shaped pacing (i.e. positive and negative pacing in different segments of the race) and variable pacing (i.e. pacing with multiple fluctuations).

In swimming, pacing in elite-standard athletes has been investigated (Lipińska, Allen, swimmers tend to adopt a parabolic-shaped pacing. For example, in elite-standard women $800 \mathrm{~m}$ freestyle swimmers, the speed profile was a shallow negative quadratic with longest time in the eleventh lap. The first and the last laps (lengths) took less 
84 time than the other laps (Lipińska et al., 2015). In elite-standard $400 \mathrm{~m}$ freestyle

85 swimmers, fast-start-even and parabolic pacing profiles were the most frequently used 86 (Mauger et al., 2012).

87 However, in addition to elite-standard athletes, since 1986, age-group swimmers have 88 competed in FINA World Masters Championships (www.fina.org/discipline/masters).

89 While we have some knowledge about the pacing in freestyle swimming for elite-

90 standard swimmers (Lipińska et al., 2015; Mauger et al., 2012; Robertson et al.,

91 2009), we have no data about pacing in age-group freestyle swimmers. The present

92 study investigated changes in swimming time by laps in age group swimmers (i.e. age

93 groups from 25-29 years to 90-94 years) competing in the FINA World Masters

94 Championships 2014 in 100 m, 200 m, 400 m, and 800 m freestyle. 


\section{Materials and Methods}

98

100

101

102

103

104

105

106

107

108

109

110

111

112

113

114

115

116

117

118

119

120

\section{Ethics approval}

The study was approved by the Institutional Review Board of St. Gallen, Switzerland.

\section{Data sampling and data analysis}

All data were obtained from the official and publicly accessible website of the FINA at www.fina.org/content/fina-masters-world-championships-results-archive. In the XV FINA World Masters Championships held in Montreal (Canada) in 2014, for each distance from $100 \mathrm{~m}$ to $800 \mathrm{~m}$ and each swimmer, times for each $50 \mathrm{~m}$ length (except $100 \mathrm{~m}$ lap in $800 \mathrm{~m}$ event) were recorded. A total of 4,481 women and men swimmers who competed in $100 \mathrm{~m}, 200 \mathrm{~m}, 400 \mathrm{~m}$, and $800 \mathrm{~m}$ freestyle were considered (Table 1). We included all women and all men for every 5-year age groups from 25-29 years to $90-94$ years to avoid a selection bias by analyzing only a limited sample of top athletes such as the top 10 or top 100 of each age group.

\section{Statistical analyses}

Statistical analyses were performed using IBM SPSS v.20.0 (SPSS, Chicago, USA).

Data were expressed as mean and standard deviation $(s)$. A mixed-design factorial ANOVA compared effects of lap and participants' sex on swimming time, where the within-groups factor was lap and the between-groups factor was participants' sex. Moreover, a mixed-design factorial ANOVA compared effects of lap and age group on swimming time separately for each sex, where the within-groups factor was lap and the between-groups factor was age group. Subsequent comparisons among laps were carried out using post-hoc Bonferroni test. The magnitude of differences among laps was examined using effect size eta squared $\left(\eta^{2}\right)$ and evaluated as: small $\left(0.010<\eta^{2} \leq 0.059\right)$, moderate $\left(0.059<\eta^{2} \leq 0.138\right)$ and large $\left(\eta^{2}>0.138\right)($ Cohen, 1988). In 
121 addition, comparison of a lap time was via the preceding lap time and was expressed

122 as a percentage using the formula $100 \times$ (lap time-preceding lap time)/preceding lap

123 time. We also compared variations in pace by participants' sex and age by a mixed-

124 effects regression model. In this model, swimmers were assigned as random variable,

125 whereas sex, age group and lap were assigned as fixed variables. We examined

126 interaction effects among these fixed variables. Akaike information criterion (AIC)

127 was used to select the final model. These analyses were performed for each swimming

128 event (i.e. $100 \mathrm{~m}, 200 \mathrm{~m}, 400 \mathrm{~m}$ and $800 \mathrm{~m}$ ) separately. Statistical significance was set

129 at alpha $=0.05$.

130

131

132

133

134

135

136

137

138

139

140

141

142

143 
144

145

146

147

148

149

150

151

152

153

154

155

156

157

158

159

160

161

162

163

164

165

166

167

168

169

\section{Results}

Table 2 summarizes the swim times for women and men for the different age groups.

In the $100 \mathrm{~m}$, there was a small lap $\times$ sex interaction $\left(P<0.001, \eta^{2}=0.045\right)$, i.e.

pacing patterns differed by sex, in which women had a larger increase in swimming time from the first lap $(0-50 \mathrm{~m})$ to the second $(51-100 \mathrm{~m})$ than men $(+11.9$ versus $+11.3 \%)$ (Figure 1). There was a large main effect for lap time $\left(P<0.001, \eta^{2}=\right.$ 0.801), in which the second lap took longer than the first $(+11.6 \%)$. In addition, there was a large lapxage group interaction both in women $\left(P<0.001, \eta^{2}=0.235\right)$ and in men $\left(P<0.001, \eta^{2}=0.185\right)$, i.e. pacing patterns differed by age group (Figure 2 ). In women, the age group 85-89 (+15.4\%) increased the swimming time in lap 2 the most and the group 35-39 the least (+9.9\%). In men, group 80-84 increased race time in lap 2 the most $(+16.2 \%)$ and the group $75-79$ the least $(+10.2 \%)$.

There was a small lapxsex interaction $\left(P<0.001, \eta^{2}=0.042\right)$ in $200 \mathrm{~m}$, too (Figure 1). Women and men differed with regards to their pacing patterns (larger changes from lap to lap in women). There was a large main effect of lap $\left(P<0.001, \eta^{2}=\right.$ $0.847)$, in which the second lap was slower than the first one $(+11.6 \%)$, the third slower than the second $(+3.8 \%)$ and the last was faster than the third one $(-2.1 \%)$ (Figure 3). There was a large lapxage group interaction, where pacing patterns differed by age group, in women $\left(P<0.001, \eta^{2}=0.195\right)$ and in men $\left(P<0.001, \eta^{2}=\right.$ 0.200) (Figure 2). In women, swimming time increased the most in lap 2 for the age group 75-79 (+7.3\%) and least for the group 30-34 (+3.7\%). Time in lap 3, time increased the most for the age group 75-79 (+2.2\%) and least for the group 30-34 $(+1.3 \%)$. In the lap 4, time decreased the most for the age group 80-84 (-2.9\%) and least for the group 30-34 (-0.1\%). In men, swimming time in lap 2 increased the most 
170 for the age group 80-84 (+6.9\%) and least for the group 35-39 (+3.0\%). In lap 3, time

171 increased the most for age group 70-74 (+2.0\%) and least for group 35-39 (+1.0\%). In

172 lap 4, time decreased the most for age group 80-84 (-4.2\%) and least for group 25-29

$173(-0.1 \%)$. Thus, larger changes in older age groups than in the younger groups

174 occurred in all laps, both in women and men. Also, there was proportionality between

175 the increase in swimming time in lap 2 and its decrease in lap 4: in women, age group

176 30-34 had least increase in lap 2 and least decrease in lap 4, whereas in men, age

177 group 80-84 had most increase in lap 2 and most decrease in lap 4.

178

179 In $400 \mathrm{~m}$ (Figure 1), there was a small lapxsex interaction $\left(P<0.001, \eta^{2}=0.033\right)$, i.e.

180 pacing patterns differed by sex, in which women decreased their swimming time from

181 the $150-200 \mathrm{~m}$ to the $201-250 \mathrm{~m}$ lap $(-0.2 \%)$ while men increased $(+0.2 \%)$. There was

182 a large main effect of lap $\left(P<0.001, \eta^{2}=0.856\right)$, in which swimming time increased

183 during the 50-100 $\mathrm{m}(+11.1 \%), 101-150 \mathrm{~m}(+2.9 \%), 151-200 \mathrm{~m}(+1.2 \%)$, remained

184 unchanged during the 201-250 $\mathrm{m}$ and again increased during the $251-300 \mathrm{~m}(+0.5 \%)$,

185 and finally decreased during the $301-350 \mathrm{~m}(-0.6 \%)$ and $351-400 \mathrm{~m}(-4.5 \%)$ (Figure

186 3). Moreover, there was a large lapxage group interaction in women $\left(P<0.001, \eta^{2}=\right.$

187 0.176) and a corresponding moderate interaction in men $\left(P<0.001, \eta^{2}=0.131\right)$, i.e.

188 pacing patterns differed by age group (Figure 2). In women, in lap 2 swimming time

189 increased the most $(+15.0 \%)$ in group $75-79$ and least $(+10.3 \%)$ in group 30-34,

190 whereas in the last lap it decreased the most in group 75-79 (-6.7\%) and least in group

$19125-29(-3.0 \%)$. In men, time in lap 2 increased the most in group 80-84 (+14.3\%) and

192 least in group 50-54 (+9.4\%), whereas time in the last lap decreased the most in group

193 65-69 (-6.2\%) and least in group 50-54 (-3.1\%). Both in women and men, the largest

194 changes in swimming time occurred in older groups and the smallest in younger 
groups. A similar trend of proportionality between lap 2 and lap 4 as in $200 \mathrm{~m}$, also occurred in $400 \mathrm{~m}$, e.g. women age group 75-79 and men group 50-54.

197

198

There was a small lap $\times$ sex interaction $\left(P<0.001, \eta^{2}=0.034\right)$ in $800 \mathrm{~m}$, too (Figure 1). Women and men differed in their pacing patterns (i.e. larger changes from 0-100 $\mathrm{m}$ to $101-200 \mathrm{~m}$, from $301-400 \mathrm{~m}$ to $401-500 \mathrm{~m}$ and in the last lap in women). There was a large main effect of lap $\left(P<0.001, \eta^{2}=0.842\right)$, in which the swimming time increased during 100-200 m (+8.8\%), 201-300 m (+1.0\%), 301-400 m (+0.5\%), 401$500 \mathrm{~m}(+0.2 \%), 501-600 \mathrm{~m}(+0.2 \%)$, and decreased during 601-700 $\mathrm{m}(-0.3 \%)$ and 701-800 m (-3.4\%) (Figure 3). There was a small lapxage group interaction in women $\left(P<0.001, \eta^{2}=0.054\right)$ and a corresponding moderate interaction in men $(P<$ $0.001, \eta^{2}=0.105$ ), where pacing patterns differed by age group (Figure 2). In women, in lap 2 swimming time increased the most for the age group 65-69 (+9.6\%) and least for the group $80-84(+5.6 \%)$, whereas in the last lap, swimming time decreased the most for the age group 60-64 $(-4.1 \%)$ and least for the group $80-84(-0.9 \%)$. In men, in lap 2 the swimming time increased the most for the age group $80-84(+12.8 \%)$ and least for the group 30-34 (6.9\%), whereas in the last lap swimming time decreased the most for the group 80-84 (-5.8\%) with the 65-69 group showing an increase $(+0.2 \%)$. The trend of larger changes in the older groups occurred only in men. However, the trend of proportionality in changes between the second and the last lap also occurred, e.g. women age group 80-84 and men group 80-84.

The findings of the mixed-effects regression analysis of the effect of participants' sex, lap and their interaction on swimming time by swimming event are summarised in Table 3, whereas the analysis of the effect of lap, age group and their interaction on swimming time is summarised in Table 4 (women) and Table 5 (men). 


\section{Discussion}

The main finding of the present study was a general pattern of pacing in the events of $100 \mathrm{~m}, 200 \mathrm{~m}, 400 \mathrm{~m}$ and $800 \mathrm{~m}$ freestyle for master swimmers. The largest increase in swimming time occurred during the second lap and the shortest time was for the last lap, except in the $100 \mathrm{~m}$. In addition to this general pattern, there was a variation in pacing by sex and age group. In $100 \mathrm{~m}, 200 \mathrm{~m}$ and $800 \mathrm{~m}$, larger changes from lap to lap occurred in women than in men. Also, a general trend that older age groups had larger changes than younger groups occurred in all distances and in both sexes.

For the longer distances such as the $400 \mathrm{~m}$ and $800 \mathrm{~m}$ freestyle, swimmers adopted parabolic pacing (Abbiss \& Laursen, 2008), where the first and the last lap were the fastest. This strategy is practically identical to elite-standard swimmers competing in $400 \mathrm{~m}$ freestyle swimming where a fast-start-even-and-parabolic pacing strategy was used (Mauger et al., 2012). Also, elite-standard women freestyle swimmers adopted a parabolic-shaped pacing in $800 \mathrm{~m}$, where the first and the last laps were faster by 6.4\% and 3.6\% (Lipińska et al., 2015). Most probably, the parabolic pacing strategy of a fast first lap, an even pacing throughout the next laps and fast last lap is the most appropriate strategy both for elite-standard and age-group swimmers who competing in high-level races. The length of a swimming performance is also important. When women and men 100-m and 200-m breaststroke swimmers were compared, faster 100-m and 200-m breaststroke swimmers had a greater competency in kinematic variables (e.g. swimming speed, stroke rate and stroke length, start, turns and finish) except stroke kinematics, which were unique to each individual (Thompson, Haljand ,\& MacLaren, 2000). 


\section{Influence of participants' sex}

248 Another major finding was the effect of participants' sex on pacing indicating larger

249 changes in swimming time by laps in women than in men. Differences in pacing

250 between women and men elite-standard swimmers have also been reported. In

251 individual medley swimmers competing at international level, men applied a positive

252 pacing strategy in the $200 \mathrm{~m}$ and $400 \mathrm{~m}$ individual medley events, whereas women

253 applied a negative pacing strategy (Saavedra et al., 2012). However, for other sports,

254 differences in pacing between women and men have been reported. For example, in

255 marathon running, men slow down faster than women (Deaner, Carter, Joyner, \&

256 Hunter, 2014). The same has been found in a 5-km run. It was assumed that the sex-

257 based difference in pacing partly reflected differences indecision making, such as

258 over-confidence, risk perception, or willingness to tolerate discomfort (Deaner \&

259 Lowen, 2016). Also others reported differences in marathon running between women

260 and men. March et al. ( 2011) reported that older runners, women, and faster runners

261 are better pacers than younger runners, men, and slower runners, respectively.

262 Nevertheless, both in women and men, similar patterns of difference occurred among 263 age groups' pacing.

\section{Influence of age}

266 There was a larger effect of age group on pacing than participants' sex. Particularly,

267 we identified larger changes in swimming time by lap in the older age groups than in

268 the younger groups. The age groups, who exhibited the larger increase in swimming

269 time in the second lap, showed the largest decrease in time in the last lap and vice

270 versa. We hypothesized that since the faster age group swimmers were the younger in

271 the present study, we would find smaller changes in the younger than in the older age

272 groups. Thus, the observed lapxage group interaction could be attributed to the slower 
swimming time of the older groups. This agreed with research on pacing in the marathon that identified stable pacing, i.e. smaller changes in the faster runners than in the slower (March et al., 2011). A curvilinear decline in endurance performance in swimming from the age 35 years to approximately the age of $60-70$ years has been reported (Reaburn \& Dascombe, 2008).

This decline has been attributed to age-related decreases in maximal oxygen uptake, maximal heart rate, stroke volume, arteriovenous oxygen difference, active muscle mass, type II muscle fibre size and blood volume (Reaburn \& Dascombe, 2008). Thus, effects of age group on pacing might be because of age-related differences in performance and physiological characteristics. However, age-related physiological characteristics might vary by sport. In contrast to $400 \mathrm{~m}$, which lasted 5-10 min, and 800 m event ( $10-20$ min duration), that rely mostly on aerobic energy transfer systems, $100 \mathrm{~m}$ (1-2 min duration) is considered a high-intensity event with $200 \mathrm{~m}$ (25 min duration) requiring a combination of aerobic and anaerobic mechanisms (Reaburn \& Dascombe, 2009). Accordingly, the age group effect on pacing in $100 \mathrm{~m}$ should be attributed to age-related decreases in morphological characteristics, muscle contractile properties, enzyme activity and lactate production (Reaburn \& Dascombe, 2009), whereas age group effects on pacing in $800 \mathrm{~m}$ would be mostly attributable age-related decrease in aerobic measures such as maximal oxygen uptake (Reaburn $\&$ Dascombe, 2008).

\section{Limitations}

The findings of the present study concerned the FINA Masters World Championships' free style swimmers who can be considered to be the best age-group competitors in the world. Thus, the pacing patterns identified should be generalized only to 
swimmers of similar level, because in lower level swimmers, different pacing (e.g. larger changes from lap to lap) is likely. Another limitation of the findings of this study might be technical characteristics of the swimming pool where the particular

301 sport event took place; it was outdoors with $50 \mathrm{~m}$ length. Performances in shorter 302 pools $(25 \mathrm{~m})$ probably impose different physiological demands because of the 303 additional turns (e.g. turns and in particular the "push" parts off the wall, aid 304 swimmers). Since the championship took place outdoors under particular 305 environmental conditions (e.g. water and air temperature), caution is needed to 306 generalize these findings in races under different environmental conditions. Moreover, 307 the present study focused on data analysis of laps and did not consider other aspects, 308 such as start times, turn times and stroke characteristics (Veiga, Roig, \& Gómez309 Ruano, 2016), which might also influence pacing. As regards to the statistical 310 analyses, it is important to note that "statistically significant" outcomes were 311 attributable simply to the high number of participants. Of more importance are the 312 effect sizes that provide information about the practical meaningfulness of the 313 findings.

\section{Practical applications}

316 The analysis of the pacing during four freestyle-swimming races in age groups of 317 master swimmers is important for researchers involved in the study of performance in 318 older athletes and for coaches working with master swimmers. Since this is the first 319 study of pacing in master swimmers, researchers might use its findings as reference in 320 future studies on pacing on master athletes. Coaches could consider the pacing 321 patterns of these data as a guide in the development of pacing strategies for their 322 athletes, because these data concern high-level swimmers who participated in the 
323 World championship. Particularly, coaches should consider the sex- and age-related

324 differences in pacing by setting sex- and age-tailored training goals. For instance, 200

325 m men swimmers should be advised to have smaller changes in swimming time from

326 lap to lap than women. With regards to age variation of pacing, older age groups

327 should be coached to decrease their swimming time in the last lap in $400 \mathrm{~m}$ more than

328 their younger counterparts.

329

330 Conclusions

331 In summary, the largest increases in swimming time occurred during the second lap

332 and the largest decreases in swimming time occurred during the last lap, except in the 333 event of $100 \mathrm{~m}$. The effect of a participants' sex was a larger percentage change of 334 speed in women than in men swimmers and the effect of age group was greater than 335 the effect of participants' sex. 


\section{References}

Abbiss, C. R., \& Laursen, P. B. (2008). Describing and understanding pacing strategies during athletic competition. Sports Medicine, 38(3), 239-252

Cohen, J. (1988). Statistical power analysis for the behavioral sciences (2nd ed.). Hillsdale, NJ: Lawrence Erlbaum Associates.

Deaner, R. O., Carter, R. E., Joyner, M. J., \& Hunter, S. K. (2014). Men are more likely than women to slow in the marathon. Medicine and Science in Sports and Exercise, 47(3), 607-616. doi: 10.1249/MSS.0000000000000432

Deaner, R. O., \& Lowen, A. (2016). Males and females pace differently in High School cross country races. Journal of Strength and Conditioning Research 2016 Mar 3. [Epub ahead of print]

Edwards, A., \& Polman, R. (2012). Pacing in sport and exercise: a psychophysiological perspective. Sports and Athletics Preparation, Performance and Psychology. Nova Science Publishers, New York.

Lipińska, P., Allen, S. V., \& Hopkins, W. G. (2015). Relationships Between Pacing Parameters and Performance of Elite Male 1500-M Swimmers. International Journal of Sports Physiology and Performance, doi: 10.1123/ijspp.2015-0117

Lipińska, P., Allen, S. V., \& Hopkins, W. G. (2016). Modeling parameters that characterize pacing of elite female 800-m freestyle swimmers. European Journal of Sport Science, 16(3), 287-292. doi: 10.1080/17461391.2015.1013996

March, D. S., Vanderburgh, P. M., Titlebaum, P. J., \& Hoops, M. L. (2011). Age, sex, and finish time as determinants of pacing in the marathon. Journal of Strength and Conditioning Research, 25(2), 386-391. doi: 10.1519/JSC.0b013e3181bffd0f

Mauger, A. R., Neuloh, J., \& Castle, P. C. (2012). Analysis of pacing strategy selection in elite 400-m freestyle swimming. Medicine and Science in Sports and Exercise, 44(11), 2205-2212. doi: 10.1249/MSS.0b013e3182604b84

Reaburn, P., \& Dascombe, B. (2008). Endurance performance in masters athletes. European Review of Aging and Physical Activity, 5(1), 31-42.

Reaburn, P., \& Dascombe, B. (2009). Anaerobic performance in masters athletes. European Review of Aging and Physical Activity, 6(1), 39-53.

Robertson, E. Y., Pyne, D.B., Hopkins, W., \& Anson, J.M. (2009). Analysis of lap times in international swimming competition. Journal of Sports Sciences, 27(4), 387-395. doi: 10.1080/02640410802641400 
Rubin, R. T., \& Rahe, R. H. (2010). Effects of aging in Masters swimmers: 40-year review and suggestions for optimal health benefits. Open Access Journal of Sports Medicine, 1, 39-44

Saavedra, J. M., Escalante, Y., Garcia-Hermoso, A., Arellano, R., \& Navarro, F. (2012). A 12-year analysis of pacing strategies in 200- and 400-m individual medley in international swimming competitions. Journal of Strength and Conditioning Research, 26(12), 3289-3296. doi: 10.1519/JSC.0b013e318248aed5

Skorski, S., Faude, O., Caviezel, S., \& Meyer, T. (2014). Reproducibility of pacing profiles in elite swimmers. International Journal of Sports Physiology and Performance, 9(2), 217-225. doi: 10.1123/ijspp.2012-0258

Tanaka, H., \& Seals, D. R. (2008). Endurance exercise performance in Masters athletes: Age-associated changes and underlying physiological mechanisms. Journal of Physiology, 586(1), 55-63.

Thompson, K. G., Haljand, R., MacLaren, D.P. (2000). An analysis of selected kinematic variables in national and elite male and female 100-m and 200-m breaststroke swimmers. Journal of Sports Sciences, 18(6), 421-431.

Veiga, S., Roig, A., \& Gómez-Ruano, M. A. (2016). Do faster swimmers spend longer underwater than slower swimmers at World Championships? European Journal of Sport Science, in print. 
Table 1 Participants in the four swimming events by sex and age group

\begin{tabular}{|c|c|c|c|c|c|c|c|c|}
\hline \multirow{2}{*}{$\begin{array}{c}\text { Age group } \\
(\text { yrs })\end{array}$} & \multicolumn{2}{|c|}{$100 \mathrm{~m}$} & \multicolumn{2}{|c|}{$200 \mathrm{~m}$} & \multicolumn{2}{|c|}{$400 \mathrm{~m}$} & \multicolumn{2}{|c|}{$800 \mathrm{~m}$} \\
\hline & Women & Men & Women & Men & Women & Men & Women & Men \\
\hline $25-29$ & 80 & 84 & 49 & 46 & 33 & 23 & 33 & 15 \\
\hline $30-34$ & 63 & 97 & 52 & 52 & 35 & 33 & 29 & 27 \\
\hline $35-39$ & 64 & 82 & 67 & 44 & 36 & 36 & 47 & 29 \\
\hline $40-44$ & 76 & 103 & 65 & 61 & 35 & 27 & 46 & 39 \\
\hline $45-49$ & 77 & 107 & 83 & 72 & 42 & 40 & 61 & 46 \\
\hline $50-54$ & 102 & 133 & 96 & 73 & 75 & 37 & 92 & 44 \\
\hline $55-59$ & 69 & 108 & 66 & 89 & 44 & 54 & 45 & 55 \\
\hline $60-64$ & 51 & 66 & 42 & 52 & 40 & 26 & 52 & 38 \\
\hline $65-69$ & 42 & 51 & 41 & 38 & 28 & 26 & 37 & 38 \\
\hline $70-74$ & 24 & 46 & 31 & 40 & 20 & 25 & 24 & 33 \\
\hline $75-79$ & 19 & 23 & 14 & 26 & 14 & 16 & 14 & 12 \\
\hline $80-84$ & 11 & 9 & 12 & 7 & 7 & 13 & 7 & 10 \\
\hline $85-89$ & 8 & 3 & 4 & 1 & 2 & 2 & 2 & 2 \\
\hline $90-94$ & 4 & & 4 & 1 & 3 & & 3 & \\
\hline Total & 690 & 912 & 626 & 602 & 413 & 358 & 492 & 388 \\
\hline
\end{tabular}

427

428

429

430

431 
Table 2 Performance (s) in the four swimming events by sex and age group

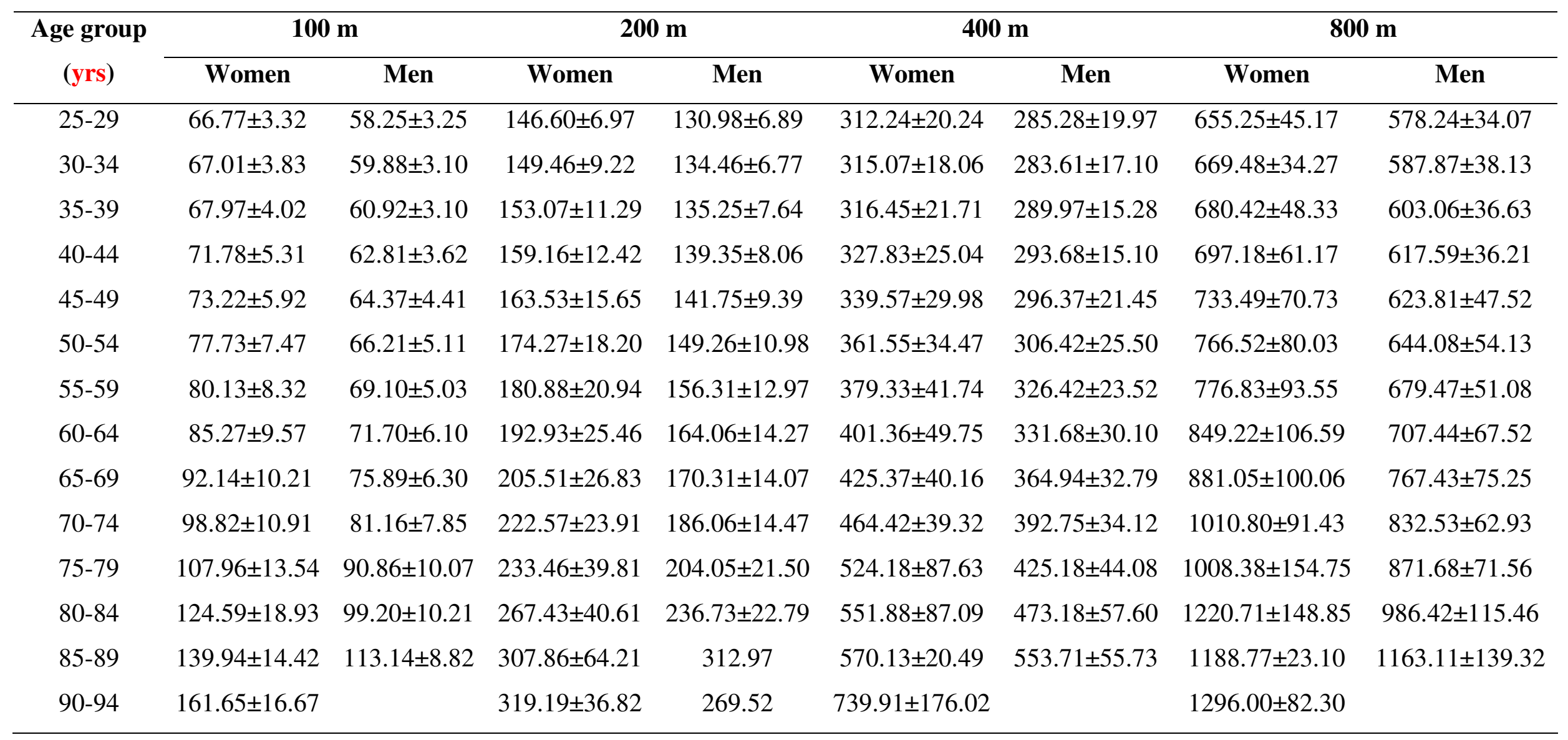


Table 3 Coefficients (C) and standard errors of estimate (SEE) from multi-variate regression models for race times of participants by sex and lap

\begin{tabular}{|c|c|c|c|c|}
\hline & & $\mathbf{C}$ & SEE & $p$ \\
\hline & Sex & 4.58 & $0.36(0.50)$ & $<0.001$ \\
\hline \multirow[t]{3}{*}{$100 \mathrm{~m}$} & Lap & 3.57 & $0.07(0.10)$ & $<0.001$ \\
\hline & Interaction sex $\times$ lap & 0.86 & $0.10(0.14)$ & $<0.001$ \\
\hline & Sex & 4.95 & $0.46(0.28)$ & $<0.001$ \\
\hline \multirow[t]{3}{*}{$200 \mathrm{~m}$} & Lap & 1.54 & $0.04(0.02)$ & $<0.001$ \\
\hline & Interaction sex $\times$ lap & 0.27 & $0.06(0.04)$ & $<0.001$ \\
\hline & Sex & 5.52 & $0.63(0.18)$ & $<0.001$ \\
\hline \multirow[t]{3}{*}{$400 \mathrm{~m}$} & Lap & 0.46 & $0.02(0.01)$ & $<0.001$ \\
\hline & Interaction sex $\times$ lap & 0.03 & $0.02(0.01)$ & 0.219 \\
\hline & Sex & 11.79 & $1.13(0.15)$ & $<0.001$ \\
\hline \multirow[t]{2}{*}{$800 \mathrm{~m}$} & Lap & 0.58 & $0.03(<0.01)$ & $<0.001$ \\
\hline & Interaction sex $\times$ lap & 0.04 & $0.04(0.01)$ & 0.348 \\
\hline
\end{tabular}

* SEE is expressed in absolute values and as percentage of mean in brackets. 
Table 4 Coefficients (C) and standard errors of estimate (SEE) from multi-variate regression models for race times of participants by lap and age group in women

\begin{tabular}{|c|c|c|c|c|c|c|c|c|c|c|c|c|}
\hline & \multicolumn{3}{|c|}{$100 \mathrm{~m}$} & \multicolumn{3}{|c|}{$200 \mathrm{~m}$} & \multicolumn{3}{|c|}{$400 \mathrm{~m}$} & \multicolumn{3}{|c|}{$800 \mathrm{~m}$} \\
\hline & $\mathbf{C}$ & SEE & $p$ & $\mathbf{C}$ & SEE & $p$ & $\mathbf{C}$ & SEE & $p$ & $\mathbf{C}$ & SEE & $p$ \\
\hline Lap & 5.95 & $0.95(1.21)$ & $<0.001$ & 3.04 & $0.52(0.30)$ & $<0.001$ & 1.41 & $0.21(0.06)$ & $<0.001$ & 1.05 & $0.35(0.04)$ & 0.003 \\
\hline Age group 25-29 & -43.95 & $2.47(3.14)$ & $<0.001$ & -39.67 & $2.85(1.62)$ & $<0.001$ & -49.24 & $3.12(0.89)$ & $<0.001$ & -78.52 & $6.33(0.81)$ & $<0.001$ \\
\hline Age group 30-34 & -44.20 & $2.49(3.17)$ & $<0.001$ & -38.82 & $2.84(1.61)$ & $<0.001$ & -48.54 & $3.11(0.89)$ & $<0.001$ & -76.41 & $6.36(0.81)$ & $<0.001$ \\
\hline Age group 35-39 & -43.08 & $2.49(3.17)$ & $<0.001$ & -38.59 & $2.82(1.60)$ & $<0.001$ & -48.75 & $3.11(0.89)$ & $<0.001$ & -75.30 & $6.25(0.8)$ & $<0.001$ \\
\hline Age group 40-44 & -42.46 & $2.48(3.15)$ & $<0.001$ & -36.54 & $2.82(1.60)$ & $<0.001$ & -47.17 & $3.11(0.89)$ & $<0.001$ & -72.53 & $6.25(0.8)$ & $<0.001$ \\
\hline Age group 45-49 & -41.83 & $2.47(3.14)$ & $<0.001$ & -35.87 & $2.81(1.60)$ & $<0.001$ & -45.74 & $3.09(0.88)$ & $<0.001$ & -68.71 & $6.2(0.79)$ & $<0.001$ \\
\hline Age group 50-54 & -40.61 & $2.46(3.13)$ & $<0.001$ & -33.05 & $2.8(1.59)$ & $<0.001$ & -43.37 & $3.05(0.87)$ & $<0.001$ & -64.31 & $6.15(0.79)$ & $<0.001$ \\
\hline Age group 55-59 & -39.09 & $2.48(3.15)$ & $<0.001$ & -31.95 & $2.82(1.60)$ & $<0.001$ & -40.81 & $3.09(0.88)$ & $<0.001$ & -62.72 & $6.25(0.8)$ & $<0.001$ \\
\hline Age group 60-64 & -36.95 & $2.51(3.19)$ & $<0.001$ & -27.98 & $2.87(1.63)$ & $<0.001$ & -38.31 & $3.1(0.88)$ & $<0.001$ & -52.91 & $6.23(0.8)$ & $<0.001$ \\
\hline Age group 65-69 & -33.74 & $2.52(3.21)$ & $<0.001$ & -24.87 & $2.87(1.63)$ & $<0.001$ & -34.81 & $3.14(0.89)$ & $<0.001$ & -49.52 & $6.3(0.8)$ & $<0.001$ \\
\hline Age group 70-74 & -32.40 & $2.61(3.32)$ & $<0.001$ & -21.62 & $2.91(1.65)$ & $<0.001$ & -30.66 & $3.2(0.91)$ & $<0.001$ & -34.36 & $6.42(0.82)$ & $<0.001$ \\
\hline Age group 75-79 & -27.71 & $2.65(3.37)$ & $<0.001$ & -19.75 & $3.11(1.77)$ & $<0.001$ & -23.49 & $3.29(0.94)$ & $<0.001$ & -34.83 & $6.67(0.85)$ & $<0.001$ \\
\hline Age group 80-84 & -20.39 & $2.82(3.59)$ & $<0.001$ & -9.98 & $3.16(1.79)$ & 0.002 & -18.29 & $3.57(1.02)$ & $<0.001$ & -7.34 & $7.24(0.92)$ & 0.311 \\
\hline Age group 85-89 & -17.17 & $2.95(3.75)$ & $<0.001$ & -7.11 & $3.87(2.20)$ & 0.067 & -17.40 & $4.72(1.34)$ & $<0.001$ & -12.58 & $9.58(1.22)$ & 0.190 \\
\hline Age group 90-94 & $0^{*}$ & $0^{*}$ & - & $0^{*}$ & $0^{*}$ & - & $0^{*}$ & $0^{*}$ & - & $0^{*}$ & $0 *$ & - \\
\hline Interaction lap×age group 25-29 & -2.56 & $0.98(1.25)$ & 0.009 & -1.39 & $0.54(0.31)$ & 0.010 & -0.94 & $0.22(0.06)$ & $<0.001$ & -0.34 & $0.36(0.05)$ & 0.344 \\
\hline Interaction lap×age group 30-34 & -2.31 & $0.98(1.25)$ & 0.019 & -1.44 & $0.54(0.31)$ & 0.007 & -1.01 & $0.22(0.06)$ & $<0.001$ & -0.42 & $0.37(0.05)$ & 0.254 \\
\hline Interaction lap×age group 35-39 & -2.74 & $0.98(1.25)$ & 0.005 & -1.18 & $0.53(0.30)$ & 0.028 & -0.93 & $0.22(0.06)$ & $<0.001$ & -0.36 & $0.36(0.05)$ & 0.315 \\
\hline Interaction lap×age group 40-44 & -1.88 & $0.98(1.25)$ & 0.054 & -1.38 & $0.53(0.30)$ & 0.010 & -0.97 & $0.22(0.06)$ & $<0.001$ & -0.51 & $0.36(0.05)$ & 0.156 \\
\hline Interaction lap×age group 45-49 & -1.82 & $0.98(1.25)$ & 0.062 & -1.22 & $0.53(0.30)$ & 0.021 & -0.96 & $0.21(0.06)$ & $<0.001$ & -0.35 & $0.36(0.05)$ & 0.326 \\
\hline Interaction lap×age group 50-54 & -1.13 & $0.97(1.23)$ & 0.244 & -1.25 & $0.53(0.30)$ & 0.018 & -0.87 & $0.21(0.06)$ & $<0.001$ & -0.41 & $0.35(0.04)$ & 0.247 \\
\hline Interaction lap×age group 55-59 & -1.35 & $0.98(1.25)$ & 0.169 & -1.04 & $0.53(0.30)$ & 0.051 & -0.95 & $0.21(0.06)$ & $<0.001$ & -0.48 & $0.36(0.05)$ & 0.185 \\
\hline
\end{tabular}




\begin{tabular}{|c|c|c|c|c|c|c|c|c|c|c|c|c|}
\hline Interaction lap $\times$ age group 60-64 & -1.06 & $0.99(1.26)$ & 0.284 & -1.40 & $0.54(0.31)$ & 0.010 & -0.89 & $0.22(0.06)$ & $<0.001$ & -0.65 & $0.36(0.05)$ & 0.071 \\
\hline Interaction lap×age group 65-69 & -0.91 & $1(1.27)$ & 0.360 & -1.42 & $0.54(0.31)$ & 0.009 & -1.00 & $0.22(0.06)$ & $<0.001$ & -0.52 & $0.36(0.05)$ & 0.154 \\
\hline Interaction lap $\times$ age group 70-74 & 0.43 & $1.03(1.31)$ & 0.679 & -0.99 & $0.55(0.31)$ & 0.074 & -0.84 & $0.22(0.06)$ & $<0.001$ & -0.28 & $0.37(0.05)$ & 0.447 \\
\hline Interaction lap $\times$ age group 75-79 & 0.42 & $1.05(1.34)$ & 0.688 & -0.67 & $0.59(0.34)$ & 0.253 & -0.77 & $0.23(0.07)$ & 0.001 & -0.24 & $0.38(0.05)$ & 0.525 \\
\hline Interaction lap×age group 80-84 & 1.01 & $1.11(1.41)$ & 0.363 & -1.18 & $0.6(0.34)$ & 0.048 & -1.16 & $0.25(0.07)$ & $<0.001$ & -0.46 & $0.42(0.05)$ & 0.274 \\
\hline Interaction lap×age group 85-89 & 3.99 & $1.17(1.49)$ & 0.001 & 1.71 & $0.73(0.41)$ & 0.020 & -0.85 & $0.33(0.09)$ & 0.010 & -0.18 & $0.55(0.07)$ & 0.747 \\
\hline Interaction lap×age group 90-94 & $0 *$ & $0 *$ & - & $0 *$ & $0 *$ & - & $0 *$ & $0 *$ & - & $0 *$ & $0 *$ & - \\
\hline
\end{tabular}

*This age group has been set to zero, because this parameter is redundant. SEE is expressed in absolute values and as percentage of mean in brackets. 
Table 5 Coefficients (C) and standard errors of estimate (SEE) from multi-variate regression models for race times of participants by lap and age group in men

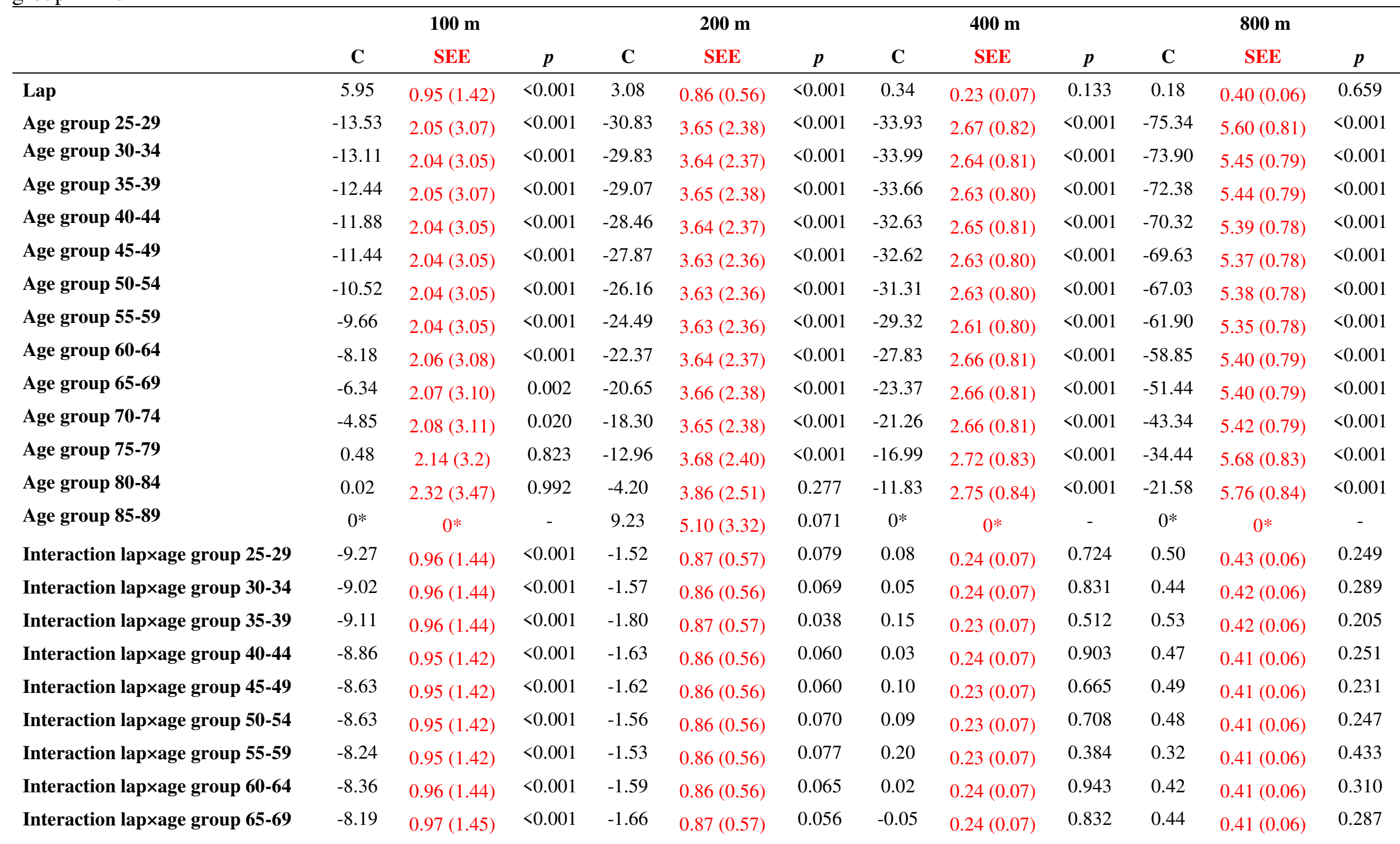




\begin{tabular}{|c|c|c|c|c|c|c|c|c|c|c|c|c|}
\hline Interaction lap×age group 70-74 & -7.42 & $0.97(1.45)$ & $<0.001$ & -1.03 & $0.87(0.57)$ & 0.236 & 0.25 & $0.24(0.07)$ & 0.286 & 0.45 & $0.42(0.06)$ & 0.280 \\
\hline Interaction lap×age group 75-79 & -7.75 & $1(1.50)$ & $<0.001$ & -1.36 & $0.87(0.57)$ & 0.119 & 0.21 & $0.24(0.07)$ & 0.396 & -0.44 & $0.44(0.06)$ & 0.310 \\
\hline Interaction lap×age group 80-84 & -4.68 & $1.09(1.63)$ & $<0.001$ & -1.60 & $0.92(0.60)$ & 0.081 & 0.39 & $0.25(0.08)$ & 0.111 & -0.11 & $0.44(0.06)$ & 0.799 \\
\hline Interaction lap×age group 85-89 & $0 *$ & $0 *$ & - & 0.65 & $1.21(0.79)$ & 0.591 & $0 *$ & $0 *$ & - & $0 *$ & $0 *$ & - \\
\hline
\end{tabular}

*This age group has been set to zero, because this parameter is redundant. 


\section{Figure legends}

Figure 1 Changes in swimming time by laps in $100 \mathrm{~m}, 200 \mathrm{~m}, 400 \mathrm{~m}$ and $800 \mathrm{~m}$ in women (dashed line) and men (solid line)

Figure 2 Changes in swimming time by laps in $100 \mathrm{~m}, 200 \mathrm{~m}, 400 \mathrm{~m}$ and $800 \mathrm{~m}$ by age groups in women and men

Figure 3 Difference (\%) in swimming time between consecutive laps in $100 \mathrm{~m}, 200 \mathrm{~m}$, $400 \mathrm{~m}$ and $800 \mathrm{~m}$ 

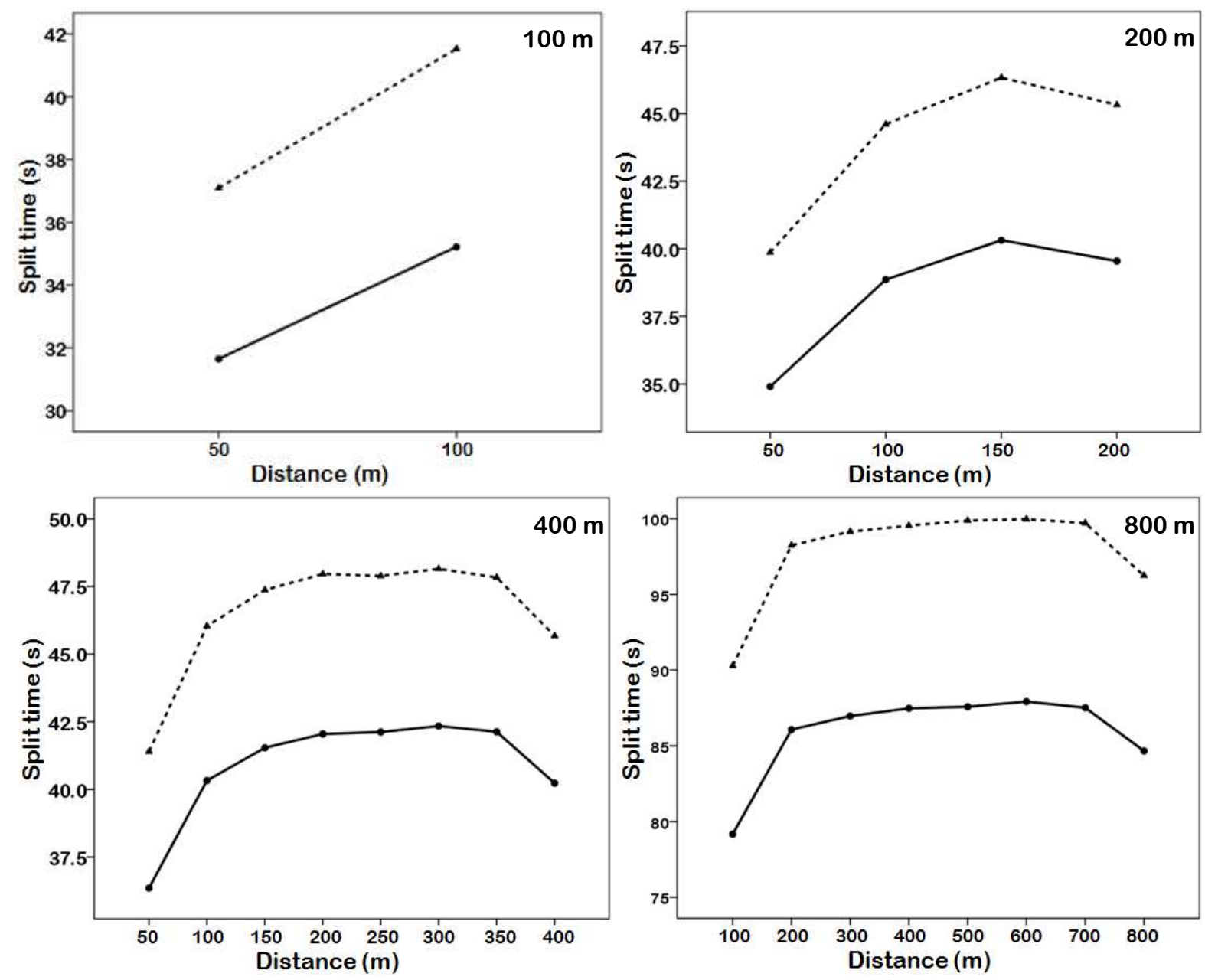

Figure 1 

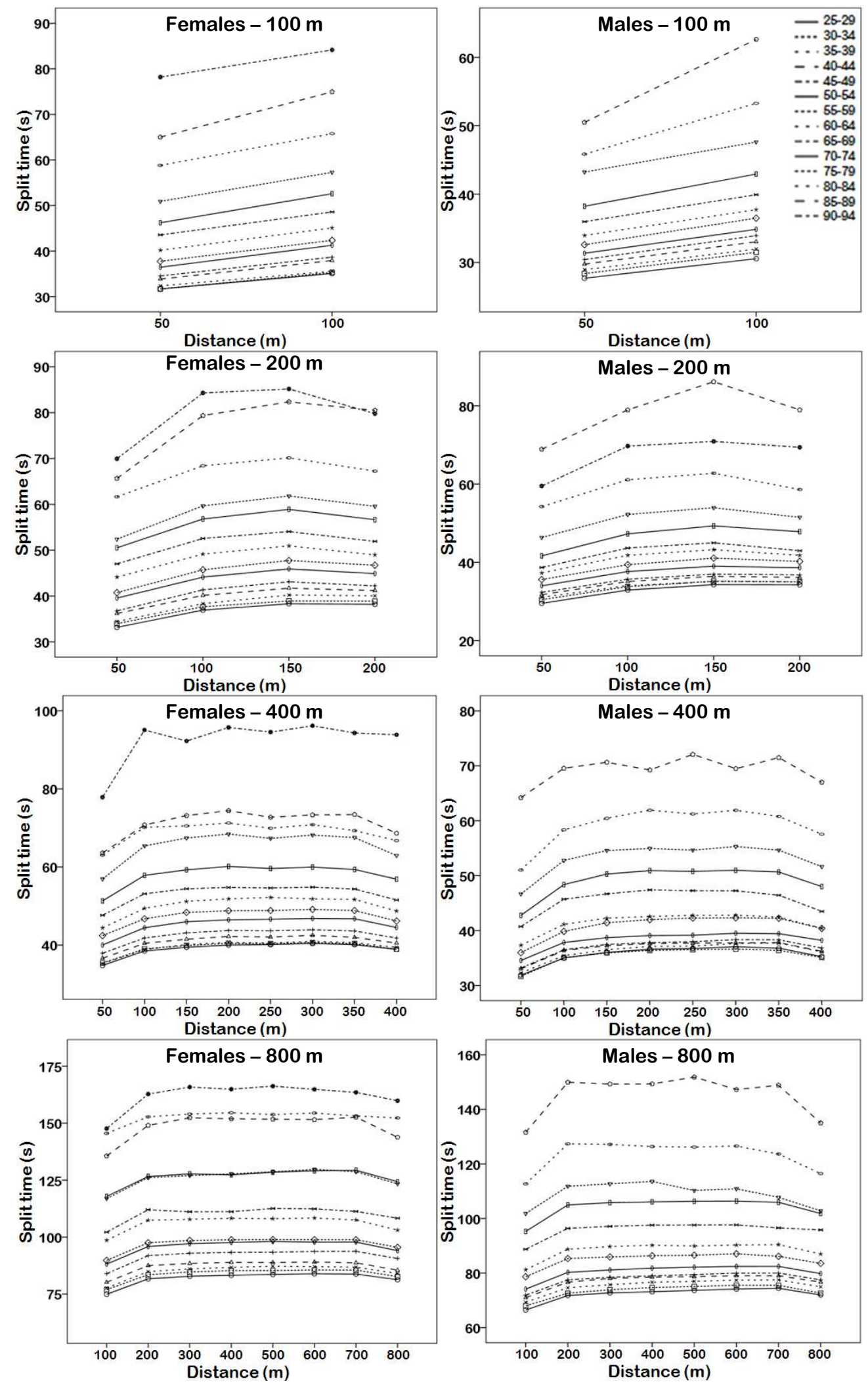

Figure 2 

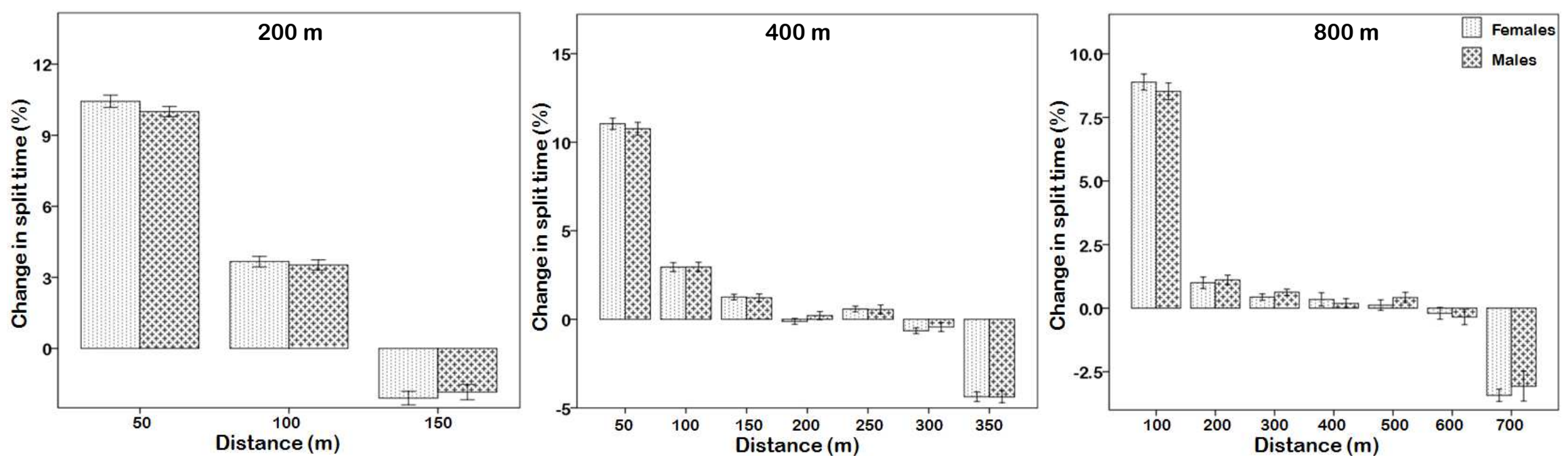

Figure 3 